\title{
Color, Temperature and Heat: Exploring University Students Mental Thoughts
}

\author{
Canlas, I. P. \\ Department of Science, College of Arts and Sciences, Leyte Normal University, Philippines
}

Copyright (C) 2016 by authors, all rights reserved. Authors agree that this article remains permanently open access under the terms of the Creative Commons Attribution License 4.0 International License

\begin{abstract}
Color, temperature and heat are among the concepts in science that are interconnected. These concepts are introduced to learners even before they enter the basic education. On the other hand, in school, it is formally introduced to them not only in science but also in the humanities. The foregoing study attempted to explore the mental thoughts of university students on color, temperature and heat using everyday circumstances that involved the said concepts. The situations in question form were administered to $503^{\text {rd }}$ year Bachelor of Secondary Education majoring Physical Science and $3^{\text {rd }}$ year Bachelor in Elementary Education majoring Content. Data gathered and collected were subjected to simple Collaizi method of data analysis to which themes and patterns were sought from the responses. Results were presented using percentages and simple frequency. The study revealed that university students possess a gap in their understanding of the above-mentioned concepts as greater majority of them possesses contradicting and inconsistent explanations. This implies that science curriculum both in the basic education and higher education needs revisiting. Likewise, an effective teaching sequence related to these concepts may be developed and used to improve students' conceptions.
\end{abstract}

Keywords Color, Temperature, Heat, Mental Thoughts

\section{Rationale}

Objects colors are reflected light rays that reach human eyes. The colors that we see are just a small part of the electromagnetic spectrum known a visible light. It includes red, orange, yellow, green, blue, indigo and violet. This sequence results to decreasing wavelength and increasing frequency. Red having lesser frequency than violet means that red posses lesser amount of energy than violet, therefore, having lower temperature than violet. On the other hand, colors that appear cool such as blue reflects wavelengths with higher frequencies while colors that appear warm reflects wavelengths with lower frequencies.
Concepts on color, temperature and heat are introduced in the university in Physical Science, Mechanics, Physics in Health Sciences, College Physics and Physics depending on the course requirement of the different degree. In the daily teaching practice of physics in the past years, the researcher noticed the inconsistent and contradicting explanations of students when given situations that involved concepts on color, temperature and heat, hence this study.

\section{Theoretical Framework}

The foregoing study is anchored on the conceptual change principle which is within the framework of constructivist theory of teaching and learning. Bruner, in his works with constructivism, he proposed that learning is an active process in which students, through their everyday social interaction, they construct and build new ideas based on their current knowledge. The works of Kearney [1], emphasized that learners build their own framework of ideas by fitting their new sensory experiences with their preexisting mental structures, instead of just acquiring them. Constructivism recognizes the role and effect of learners' preconceptions or prior knowledge in teaching and learning, hence the need to identify them through diagnostic test or pretest.

In addition, Sutherland [2] in her works on conceptual change principle, she posed that to understand science, learning must be viewed as a process of conceptual change. As such, it is important to know the preconceptions and prior knowledge of the students to be able to develop and implement a more effective strategy in teaching. This will allow the teacher to confirm the correct prior knowledge, build up limited knowledge and correct alternative conceptions.

\section{Literature Review}

There had been a number of similar and related studies that were found in literature. These studies can be clustered into conceptual assessment [3, 4], conceptual assessment and 
development of intervention [5,6] and development of conceptual assessment $[7,8,9]$..

Along conceptual assessment and evaluation, Saudt \& Forman [4] revealed that young children have already definite ideas about temperature and heat even before they get formal instruction of these concepts in school. Moreover, they found that these preconceptions were often inconsistent to the scientific views. In addition, preconceptions and misconceptions were determined among different races as indicated by the work of Tanahoung, et al [10] when they surveyed Thai and Australian introductory physics students' understanding on heat and temperature. Similar studies were also conducted across different age groups. Chu et al [3] found that years of schooling have improved the conceptual understanding of thermal concepts among students however; they found that $25 \%-55 \%$ of these students, depending on the age group, have trouble in applying thermal concepts to everyday context. In addition, the works of Borroguero et al [11] along color, Alwan [12], Prince, Vigeant and Nottis [13] Pathare and Pradhan [14] along heat and temperature and Potvin, Desmeules and Sy [15] along fire identified a number of misconceptions.

Most of these studies were focused on the context of heat and temperature while a few were focused on color perception. Hence, this study was designed to find out the consistencies of students understanding on color, heat and temperature.

\section{Objectives}

This study attempted to explore the mental thoughts of teachers and students along color, temperature and heat.

Specifically, it sought to find out the explanations of teachers and students on the following:

1. Which clothes to wear during hot seasons? (Black or white)

2. Which clothes to wear during cool seasons? (Black or white)

3. Which color is important in photosynthesis?

4. Which color of flame is the coolest? Hottest?

\section{Methodology}

The foregoing is a descriptive study that aimed to explore the mental thoughts of teachers and students along color, temperature and heat.

Four (4) questions were given to 2503 rd year Bachelor of Secondary Education (BSED) majoring Physical Sciences and 3rd year Bachelor in Elementary Education (BEED) majoring Content students enrolled in a course in Optics and Astronomy and Frontiers in Science.

The BSED-Physical Sciences students have already taken courses on Biological Sciences, Physical Sciences, Earth and Environmental Sciences, Mechanics and Inorganic Chemistry prior to taking a course in Optics. Meanwhile,
BEED-Content students have already taken Biological Sciences, Physical Sciences, Earth and Environmental Science and Inorganic Chemistry prior to taking a course in Astronomy and Frontiers in Science.

Likewise, the same questions were given to 150 public secondary school science teachers.

These questions were freely answered. Responses and explanations were tabulated; then, patterns and themes were sought and reported in this study.

Individual and group interviews were conducted as the need arises to verify and confirm responses and explanations.

Data analysis includes simple frequency counts and percentages from the themes identified using simple Collaizi method.

\section{Results and Findings}

Which clothes to wear? (Black or white)

Results show that all of the respondents both the teachers and students claimed to wear white during hot seasons. In the case of the students, all claimed to wear black during cold seasons while majority (95\%) of the teachers claimed to wear black during cold seasons. Most explanations revolved around the concept that white reflects heat while black absorbs heat. The following are excerpts from the written explanations and selected interviews from the respondents.

Students' responses.

"During hot season, wearing white reflects heat."

"An white kay nakakareflect hin heat amu nga kun mapaso maupay isul-ot. (White reflects heat that's the reason why it is nice to wear it during warm seasons.)"

"An busag nareflect hin heat amu nga maupay hiya isul-ot kun tagsirak. (White reflects heat, the reason why it is nice to wear it during warm season.)"

Teachers' responses.

"White reflects heat so it will not be absorbed by the body."

"White color reflects heat so it is good to wear it during warm seasons."

Students' responses.

"Itom it maupay nga na absorb hin heat amu nga asya dapat isul-ot hin taghagkot. (Black is a good absorber of heat hence, you should wear it during cold seasons.)"

"Kun taghagkot, dapat mag absorb ka hin heat para ka mamaso. It black asya la it naabsorb hin damo nga heat. (During cold seasons, you should absorb heat so that you will feel warm. Black absorbs more heat.)"

Teachers' responses.

"Black absorbs heat so you wear it during cool season to warm your body."

"Wearing black absorbs the heat so you will not feel cold."

"Black is a good absorber of heat, wear it to avoid feeling cold."

In Physics, heat is a flow of energy and the law says that 
heat moves from a region of higher temperature to a region of lower temperature. During hot season, the environment is warmer than the body; hence, it is just right to wear white because you do not want heat from the environment to be absorbed by your body. Meanwhile, during cold seasons, the body is cooler than the environment; hence, wearing black would result to draining of heat from the body to the environment.

Colors and photosynthesis

Results show that majority of the respondents both the teachers and students claimed green as important. Explanations revolved around the concept that green light is the one being absorbed by the plants to aid photosynthesis.

Students' responses.

"Yellow is the color of the sunlight and green are the plants."

"It is used for the coloring of the plants."

Teachers' responses.

"It helps the plant to synthesize because the dominant color of plant is green."

"Because as light hits the plants, the dominant colors are green, yellow, orange and these are absorbed by the chloroplasts."

The scientific worldview suggests that the colors we perceive in our everyday life are the colors that are reflected by the objects around us. For example, an object appears red because all colors are absorbed by the object except red which is reflected, hence reaching the eyes of the observer, the object appearing then to be red. This is illustrated in Figure 1.

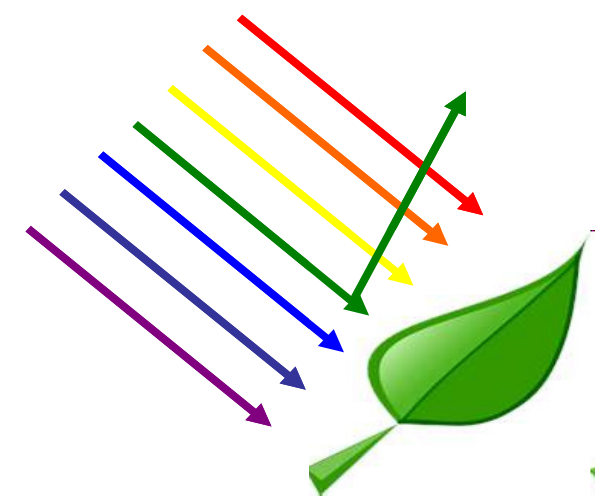

Figure 1. Scientific worldview of light absorption in photosynthesis

Results show that majority of the respondents think that the colors they commonly see among plants (leaves, flowers, fruits) are those colors that are perceived as most useful. These include green and shades near to green such as yellow. This was confirmed during the selective individual interviews.

Meanwhile, the colors not often seen among plants such as indigo, violet and blue are those that were deemed by the respondents to be least useful. This is being confirmed by the individual interviews conducted.

Students' responses.

"Because as we see in our environment, we see more green, orange and yellow."

"There is no color blue that I have seen among plants and fruits."

Teachers' responses

"These colors (blue, indigo, violet) are not needed because they represent the cold and the cold is the absence of heat, without heat photosynthesis is not possible."

Figure 2 shows how majority of the respondents perceive and understand the process of seeing and color formation in the case of light absorption in photosynthesis.

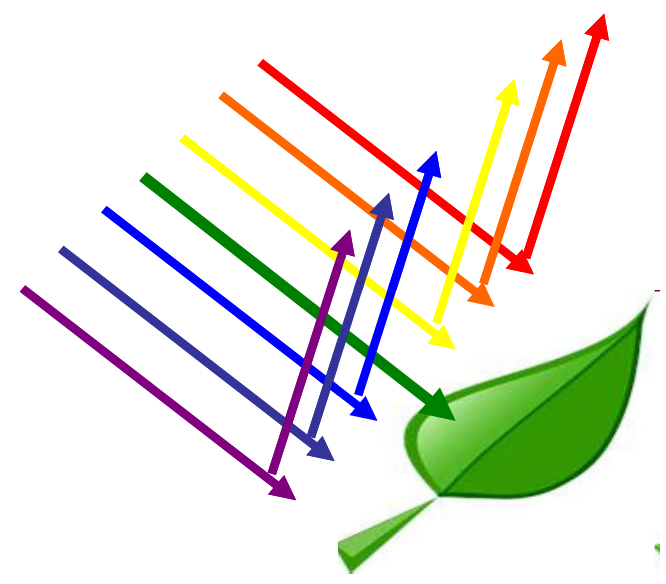

Figure 2. Respondents' conception of light absorption in photosynthesis

Colors and flames

Results revealed that majority $(60 \%)$ of the students claimed that blue flame and shades near to blue such as white and bluish white are the coolest while (40\%) claimed that red flame or shades near to red such as orange and yellow are the coolest flame.

On the other hand, majority of the teachers $(88 \%)$ claimed that red flame or shades near to red such as yellow orange, orange and yellow to be cooler while (22\%) claimed that blue flame or shades near to blue is cooler.

Scientifically, blue flames emit wavelengths with higher frequencies while red flames emit wavelengths with lower frequencies; hence, blue flames are hotter while red flames are cooler.

\section{Implications}

It is therefore implied that there exist a serious gap in the understanding of both teachers and students on the relationship of color, temperature and heat. The respondents failed to correctly trace the flow of energy (heat) from one system to another system and to properly apply it in their daily lives. Moreover, both respondents failed to comprehend the relationship of color and temperature. To them, brighter color such as yellow, red and orange is warmer while darker color such as blue green and violet is cooler. In addition, the respondents failed to comprehend and understand that the colors we see are the colors of the reflected light rays from the object. 


\section{Recommendations}

On the result

1. A review on the learning competencies related to color, temperature and heat may be done both in the basic education and general education. A checkpoint may be established to find out whether or not these competencies were mastered by learners.

2. A carefully designed teaching sequence may be implemented during the initial formal introduction of the above-involved concepts in the basic education.

3. An in service training focusing on upgrading the mastery of the subject matter may be conducted to teachers especially non-science majors.

On the study

1. Similar study may be conducted across ages, level and race to verify the results reported in this study.

2. A study on the origin of their present thoughts and how can it be changed effectively and efficiently may be done.

3. More phenomena related to the above concepts may be included to check the strength of understanding learners hold on these concepts.

\section{REFERENCES}

[1] Kearney, Matthew Denis (2002) Classroom Use of Multimedia-Supported Predict-Observe-Explain Tasks to Elicit and Promote Discussion about Students' Physics Conceptions. (Doctoral Dissertation, Curtin University of Technology, 2002) from http://espace.library.curtin.edu.au/.

[2] Sutherland, Erin Combs (1997) A study of applying conceptual change research to the secondary physics classroom in the area of mechanics. (Doctoral Dissertation, Peabody College for Teachers of Vanderbilt University, 1997) Dissertation Abstracts International, 58 (12).

[3] Chu, H. E. et al. Evaluation of Students' Understanding of Thermal Concepts in Everyday Contexts International Journal of Science Education, 34 (10), 1509-1534 (2012)

[4] Staudt, C. and Forman, G. Sensing Science: Temperature and Heat Readiness for Early Elementary Students The Concord
Consortium Research and Publications retrieved from concord.org/publications/newsletter/2014-spring/sensing science

[5] Hitt, A. M. and Townsend, J. S. The Heat is On! Using Particle Models to Change Students' Conceptions of Heat and Temperature Science Activities: Classroom Projects and Curriculum Ideas, 52 (2), 45-52 (2015)

[6] Turgut, U. Gurbus, F. Effect of Conceptual Change text approach on removal of students' misconceptions about heat and temperature International Journal of Innovative Learning, 11 (4), (2012)

[7] Gurcay, D. and Gulbas, E. Development of three-tier heat, temperature and internal energy diagnostic test Research in Science and Technological Education, 33 (2), 197-217 (2015)

[8] Prince, M., Vigeant, M. and Nottis, K. Development of the Heat and Energy Concept Inventory: Preliminary Results on the Prevalence and Persistence of Engineering Students' Misconceptions Journal of Engineering Education, 101 (3), 412-438 (2012)

[9] Yeo, S. and M. Zadnik. Introductory Thermal Concept Evaluation: Assessing Students' Understanding The Physics Teacher 39, 496-505 (2001)

[10] Tanahoung, C. et. al. Surveying Thai and Sydney introductory physics students' understandings of heat and temperature. Paper presented in a poster and part of the conference proceedings of UniServe Science Assessment Symposium in 2006.

[11] Borroguero, G, M. et al. Detection of Misconceptions about Color and an Experimentally tested proposal to combat them International Journal of Science Education, 35 (8), 1299-1324 (2013)

[12] Alwan, A. A. Misconception of Heat and Temperature Among Physics Students Procedia-Social and Behavioral Sciences, 12, 600-614 (2011)

[13] Prince, M., Vigeant, M. and Nottis, K. Using inquiry-based activities to repair student misconceptions related to heat, energy and temperature Frontiers in Education Conference, $1-5(2012)$

[14] Pathare, S, and H. C. Pradhan. Students' Alternative Conceptions in Pressure, Heat and Temperature Trends in Science Education Research, 38-42 (2005)

[15] Potvin, P., Desmeules, Y. S., and Sy, O. Exploring Secondary Students' Conceptions about Fire using a Two-Tier, True/False, Easy to Use Diagnostic Test Journal of Education in Science, Environment and Health, 1 (2), 63-78 (2015) 